\title{
Predicting the Fatigue Life of an AlSi9Cu3 Porous Alloy Using a Vector-Segmentation Technique for a Geometric Parameterisation of the Macro Pores
}

\author{
Dejan Tomažinčič ${ }^{1, *}$, Žiga Virk ${ }^{2}$ (D), Peter Marijan Kink ${ }^{2}$, Gregor Jerše ${ }^{2}$ and Jernej Klemenc ${ }^{1}$ (D) \\ 1 Faculty of Mechanical Engineering, University of Ljubljana, Aškerčeva 6, 1000 Ljubljana, Slovenia; \\ jernej.klemenc@fs.uni-lj.si \\ 2 Faculty of Computer and Information Science, University of Ljubljana, Večna pot 113, 1000 Ljubljana, \\ Slovenia; Ziga.Virk@fri.uni-lj.si (Ž.V.); PeterMarijan.Kink@fri.uni-lj.si (P.M.K.); Gregor.Jerse@fri.uni-lj.si (G.J.) \\ * Correspondence: dejan.tomazincic@fs.uni-lj.si; Tel.: +386-1-4771-201
}

Citation: Tomažinčič, D.; Virk, Ž Kink, P.M.; Jerše, G.; Klemenc, J. Predicting the Fatigue Life of an AlSi9Cu3 Porous Alloy Using a Vector-Segmentation Technique for a Geometric Parameterisation of the

Macro Pores. Metals 2021, 11, 72.

https://doi.org/10.3390/met11010072

Received: 3 December 2020

Accepted: 28 December 2020

Published: 31 December 2020

Publisher's Note: MDPI stays neutral with regard to jurisdictional clai$\mathrm{ms}$ in published maps and institutional affiliations.

Copyright: (C) 2020 by the authors. Licensee MDPI, Basel, Switzerland. This article is an open access article distributed under the terms and conditions of the Creative Commons Attribution (CC BY) license (https:// creativecommons.org/licenses/by/ $4.0 /)$.

\begin{abstract}
Most of the published research work related to the fatigue life of porous, high-pressure, die-cast structures is limited to a consideration of individual isolated pores. The focus of this article is on calculating the fatigue life of high-pressure, die-cast, AlSi9Cu3 parts with many clustered macro pores. The core of the presented methodology is a geometric parameterisation of the pores using a vector-segmentation technique. The input for the vector segmentation is a $\mu$-CT scan of the porous material. After the pores are localised, they are parameterised as 3D ellipsoids with the corresponding orientations in the Euclidian space. The extracted ellipsoids together with the outer contour are then used to build a finite-element mesh of the porous structure. The stress-strain distribution is calculated using Abaqus and the fatigue life is predicted using SIMULIA fe-safe. The numerical results are compared to the experimentally determined fatigue lives to prove the applicability of the proposed approach. The outcome of this research is a usable tool for estimating the limiting quantity of a structure's porosity that still allows for the functional performance and required durability of a product.
\end{abstract}

Keywords: AlSi9Cu3 alloy; macro porosity; vector segmentation; elliptical pore model; high-pressure die-casting

\section{Introduction}

The high-pressure, die-casting process is one of the most competitive manufacturing processes for light-weight aluminium products in the automotive, aircraft, etc. industries because of its possibilities for automation and the economies of scale. In addition, aluminium alloys have a good strength-to-weight ratio [1]. On the other hand, the inherent consequences of the high-pressure, die-casting process include geometric inhomogeneities in the products [2] that are difficult to avoid if the manufacturing process is optimised for reducing the cost-per-part. If a proportion of the macro pores are large when compared to the non-porous material, such a material state is often referred to as foam [3]. Sometimes significant macro porosity is deliberately introduced into the structural part to reduce its mass and improve its energy-dissipation ability [4]. However, macroscopic geometric inhomogeneities (e.g., pores) have a much more detrimental effect on the structure's fatigue life than micro anomalies (e.g., interstitial voids) [5,6].

In the distant past a material's structural load-carrying capacity was based on static tests and wear and/or corrosion monitoring [7]. It was only after the incidents involving the De Havilland Comet aircraft that fatigue-related criteria began to be considered for predicting the service life of structural parts and components $[7,8]$. Nowadays, most of the load-carrying structures in air- and ground transport are optimised for a target fatigue life. For structural parts, the fatigue life is either experimentally determined or 
numerically predicted for the defined loading conditions. If the load-carrying structure is made of a homogeneous material, its fatigue life can be predicted with commercial software packages. One of them, i.e., SIMULIA, was also applied in our research. Its Abaqus module was applied to calculate the stress-strain distribution, while the fe-safe module was applied to calculate the fatigue life. To determine the stress-strain distribution in a structure to which prescribed boundary conditions and repetitive loading are applied, material data in the form of a cyclic $\sigma-\varepsilon$ curve are needed. Calculating the fatigue life requires a durability curve, which in our case was a Coffin-Manson $\varepsilon_{a}-N$ curve. The two material-data curves for the AlSi9Cu3 alloy that were applied here were determined in our previous research using strain-controlled fatigue experiments with constant and step-wise-increasing strain amplitudes [9]. The alternative would be to use the material data from existing databases $[10,11]$, but this data can be unreliable if the settings of the high-pressure, die-casting processes were not equivalent for the considered structure and the data from the literature. To calculate the fatigue life as accurately as possible it was decided to follow a continuum-damage mechanics principle that was combined with a low-cycle fatigue approach. Even though the double-linear-damage-accumulation rule generally yields better fatigue-life estimations [12,13], it was decided to use the lineardamage accumulation rule in our research due to its simplicity and its straightforward calculation of the fatigue life. The latter is based on experimental observations and was introduced by Miner [14] from the Douglas Aircraft Company and Palmgren [15] from the SKF company, and it is still referred to today as the Palmgren-Miner damage accumulation rule [16].

The focus of the research was on the implementation of a methodology for predicting the fatigue life of specific cases of high-pressure, die-cast specimens that were made of the aluminium alloy Alsi9Cu3 and contained well-developed clusters of many macro pores. There has been almost no published research on this topic to date, because most of the research was focused on structures with single isolated pores [17,18]. Theoretical results for structures with groups of pores were published by Wang et al. [19], but not for the same material that was used in our case. In our research the influence of the extensive, clustered, and random macro porosity on the fatigue life of simple specimens was experimentally estimated and numerically analysed. The basic research on the geometric detection and isolation of pores that were modelled using 3D ellipsoids was performed before using a voxel technique by Borovinsek et al. [20,21]. There are two main reasons why we expanded our research that was based on the voxel technique. For the first time, different pore geometries were linked to the metallurgical process that cause them. Besides, it was expected that the use of the vector-segmentation algorithm to detect, isolate, and model the pores with the 3D ellipsoids would result in an improved geometric characterisation regarding the orientation of the dominant elliptical pores. This puts the vector-segmentation technique at the core of the research, since the appropriateness of the fatigue-life calculations is predominantly influenced by the macroscopic geometric characteristics of the pores. Besides the prediction accuracy, the consumption of processing time will also be a matter of comparison between the two approaches for the pore detection and isolation. In this part of the research, we expected to obtain guidelines on using the more accurate but slower geometry-characterisation methods as an alternative approach to the application of faster, but less accurate, methods.

The article is structured as follows. In the second section, first the high-pressure, die-casting process is presented, together with an analysis of metallurgical defects. Then a theoretical background of the applied vector-segmentation algorithm is explained. At the end of the second section the applied methodology for the fatigue-life calculation is explained. In the third section the experimental data and numerical results are compared. This is followed by sections covering the discussion, conclusions, acknowledgements, and a list of references. A nomenclature is presented in Table 1. 
Table 1. Nomenclature.

\begin{tabular}{|c|c|c|}
\hline Symbol & Unit & Description \\
\hline$a_{t}, b_{t}, c_{t}$ & $(/)$ & Vertices of a triangle \\
\hline$b$ & $(/)$ & Fatigue strength exponent \\
\hline$c$ & $(/)$ & Fatigue ductility exponent \\
\hline$l_{0}$ & $(\mathrm{~mm})$ & Gauge length (extensometer) \\
\hline$x$ & $(\mathrm{~mm})$ & Space coordinate \\
\hline$x^{*}$ & $(\mathrm{~mm})$ & Coordinate of a centre of gravity \\
\hline$n^{\prime}$ & $(/)$ & Cyclic strain hardening exponent \\
\hline$p$ & $(/)$ & Parameter of vertices' influence (and Porosity) \\
\hline$A$ & $\left(\mathrm{~mm}^{3}\right)$ & Three-dimensional solid \\
\hline$D$ & $(/)$ & Accumulated fatigue damage \\
\hline$E$ & $(\mathrm{MPa})$ & Young's modulus \\
\hline$J$ & (Nmm) & Second (deviatoric) momentum of volume \\
\hline$K^{\prime}$ & $(\mathrm{MPa})$ & Cyclic strength coefficient \\
\hline$M$ & $(/)$ & Matrix of vertices and their influence \\
\hline$N_{f}$ & $(/)$ & Number of cycles to fracture \\
\hline$N_{i}$ & $(/)$ & Number of cycles to crack initiation \\
\hline$R$ & $(/)$ & Stress ratio \\
\hline$S$ & $(/)$ & Segmented component \\
\hline$V$ & $\left(\mathrm{~mm}^{3}\right)$ & Volume of a solid element \\
\hline$\varepsilon$ & $(/)$ & Strain \\
\hline$\varepsilon_{a}$ & $(/)$ & Strain amplitude \\
\hline$\varepsilon_{f}^{\prime}$ & $(/)$ & Fatigue ductility coefficient \\
\hline$\varepsilon_{\text {nom }}$ & $(/)$ & Nominal strain \\
\hline$\varepsilon_{\text {true }}$ & $(/)$ & True strain \\
\hline$v$ & $(/)$ & Poisson's ratio \\
\hline$\rho$ & $\left(\mathrm{g} / \mathrm{cm}^{3}\right)$ & Density \\
\hline$\sigma$ & (MPa) & Stress \\
\hline$\sigma_{f}^{\prime}$ & $(\mathrm{MPa})$ & Fatigue strength coefficient \\
\hline$\sigma_{i}$ & (MPa) & Maximum stress \\
\hline$\sigma_{m}$ & $(\mathrm{MPa})$ & Mean stress in the cycle \\
\hline$\sigma_{\text {nom }}$ & (MPa) & Nominal stress \\
\hline$\sigma_{\text {true }}$ & (MPa) & True stress \\
\hline$\kappa_{t}$ & $(/)$ & Surface finish factor \\
\hline$\Delta l$ & $(\mathrm{~mm})$ & Length change \\
\hline$\Delta \varepsilon$ & $(/)$ & Strain range for the cycle \\
\hline$\Delta \varepsilon_{n}$ & $(/)$ & Normal strain \\
\hline$\Delta \gamma$ & $(/)$ & Shear strain \\
\hline
\end{tabular}

\section{Materials and Methods}

\subsection{Specimen Manufacture and Analyses of the Metallurgical Defects}

The high-pressure, die-casting, manufacturing process results in different material and structural defects that need to be geometrically characterized [22,23]. A schematic presentation of these defects on different scales is given in Figure 1. The notch effects occurring at these defects often turn out to be fatigue-crack initiation spots. On the nano-micro scale, the smallest inhomogeneities are either voids in the crystal structure (1), substitution atoms (2) or interstitial atoms (3). The line inhomogeneities are in the form of edge dislocations (4) or screw dislocations (5). On the meso-scale, different kinds of particles or interstitials occur, which have a different chemical structure than the basic material (6-9) and cause stress concentrations at their boundaries. Inhomogeneities that can be observed with the naked eye are macro-scale defects, e.g., macro cracks (10) and macro pores (11). The basic characterisation is achieved by determination of the defect volumes. However, to improve the fatigue-life prediction also the other geometric characteristics of the defects need to be estimated, i.e., pore radii or the spatial orientation and half-axes if the pores are modelled with ellipsoids. These geometric properties significantly influence the notch effects. The spectrum of inhomogeneities makes fatigue-crack prediction a complex task. Consequently, a primary decision in our research was that the only relevant 
inhomogeneities are the ones on the largest scale of appearance, as they are decisive for a crack's initiation and growth. This means that the macro porosity was considered as the primary influential criterion in our case. Even though the macro porosity can be detected visually, it still needs a proper geometric characterisation for an adequate fatigue-life prediction.

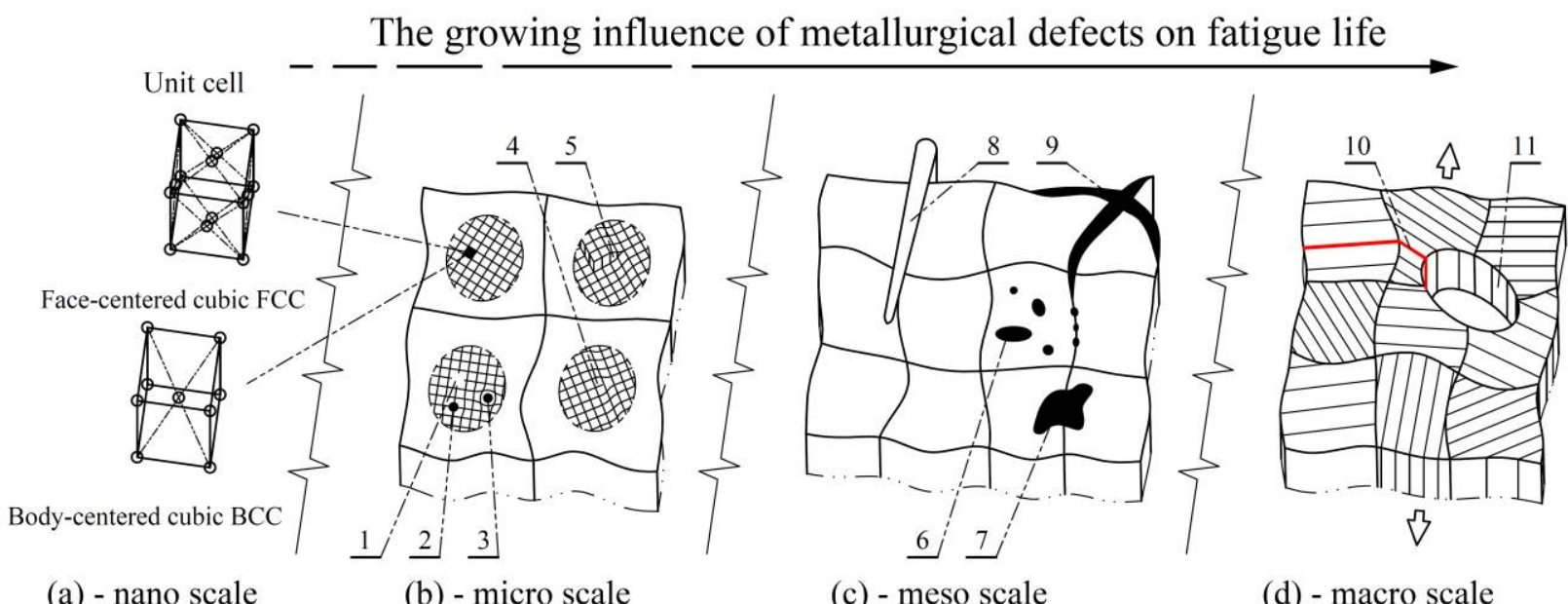
(a) - nano scale
(b) - micro scale
(c) - meso scale
(d) - macro scale

Figure 1. Material and structural defects on different scales of observation. (a) Crystal lattice; (b) vacancy, substitutional and interstitial atom, edge and screw dislocation; (c) impurities, particles; (d) crack and void.

To systematically analyse the influence of macro porosity on the fatigue life a series of experiments was performed using cylindrical, dog-bone-shaped specimens with a 9-mm diameter and a $22.5 \mathrm{~mm}$ gauge length-see Figure 2. The specimen geometry followed the recommendations of the ASTM E6060 standard. The specimens were manufactured in a foundry dealing with large-series production. The same high-pressure, die-casting machine was used as for the serial production of automotive components, i.e., a 420-ton 42D Classic machine (Bühler AG, Uzwil, Schweiz) with a cold chamber. The die tool and the manufactured specimens are presented in Figure 3. To introduce the clusters of macro porosity into the gauge part of the specimens, the conventional high-pressure, die-casting process was adapted as described below.

The melted alloy AlSi9Cu3 (Figure $3 a$ and Table 2) was poured into a casting form (Figure 3b), which has a single nest (cavity) for six specimen shapes (Figure 3c). The closing force was $4100 \mathrm{kN}$. The temperature of the melt was $700{ }^{\circ} \mathrm{C}$. The nominal stationary temperature of the casting form should be $120{ }^{\circ} \mathrm{C}$. To introduce porosity to the whole geometry of the specimens, the melt was cast into a form that was not heated to its nominal temperature. In addition, the pressure in the final casting stage was not applied. In this way the amount of porosity that was introduced into the specimens depended on the temperature of the form. It reached its nominal value of $120{ }^{\circ} \mathrm{C}$ after few tens of shots, because the form was water-cooled with a coolant temperature of $60^{\circ} \mathrm{C}$. After the casting process the specimens were not additionally processed in their gauge part, with the exception of the burr removal. They were also not artificially aged before the fatiguelife experiments. The specimens with various levels of macro porosity are presented in Figure 2.

Table 2. AlSi9Cu3 alloy designation according to different standards.

\begin{tabular}{cccccc}
\hline ISO & EN 1706 & EU & Germany & Japan & Swedish \\
- & - & EN & DIN, WNr & JIS & SS \\
AlSi9Cu3(Fe) & AC 46000 & ENAC & 3.2163 & ADC10 & Type 4250 \\
- & AlSi9Cu3(Fe) & AlSi9Cu3(Fe) & GD-AlSi9Cu3 & - & - \\
\hline
\end{tabular}




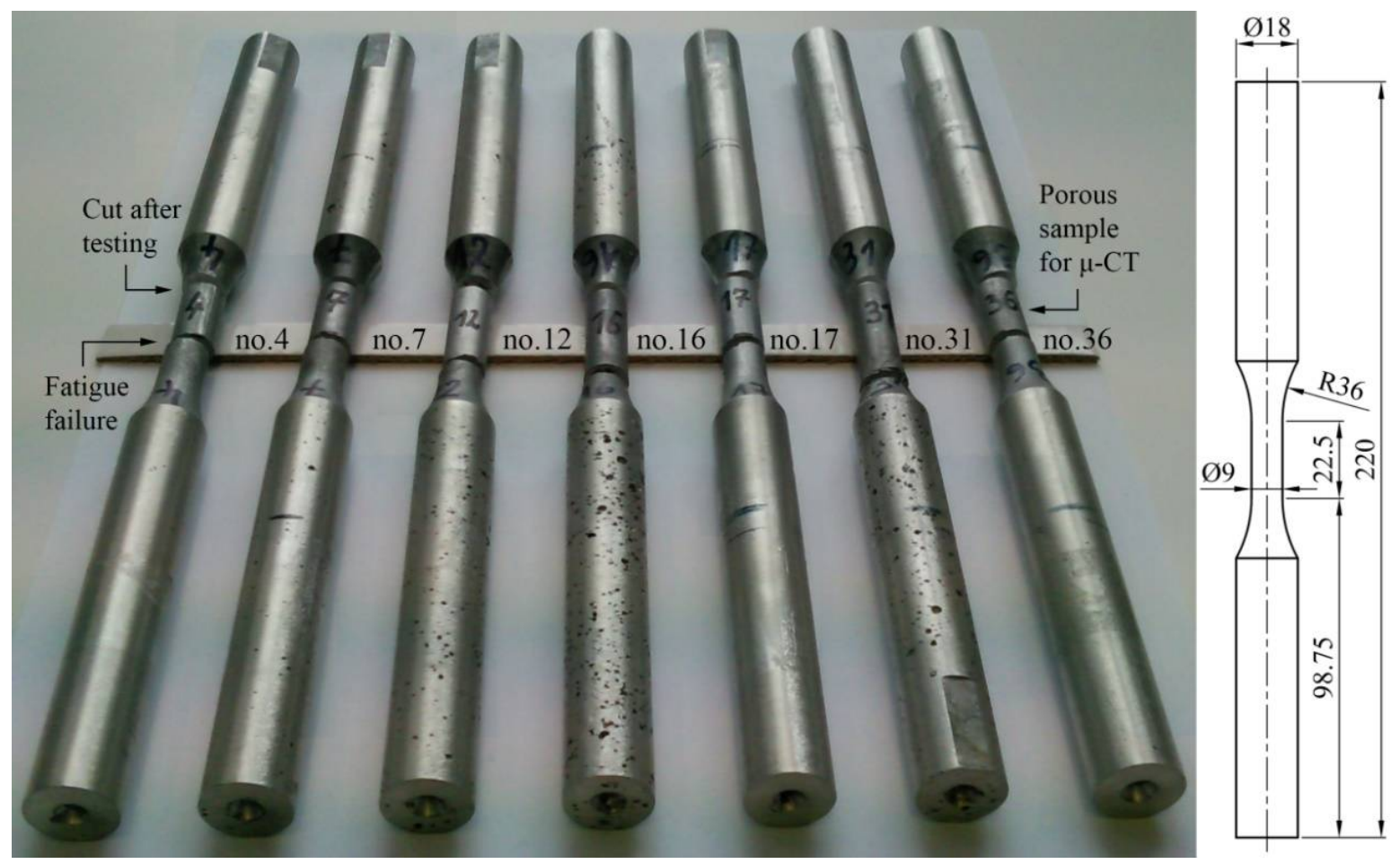

Figure 2. (Left) specimens from AlSi9Cu3 alloy with clusters of macro pores (after the low-cycle fatigue experiments); (right) design drawing of a specimen (dimensions are in $(\mathrm{mm})$ ).
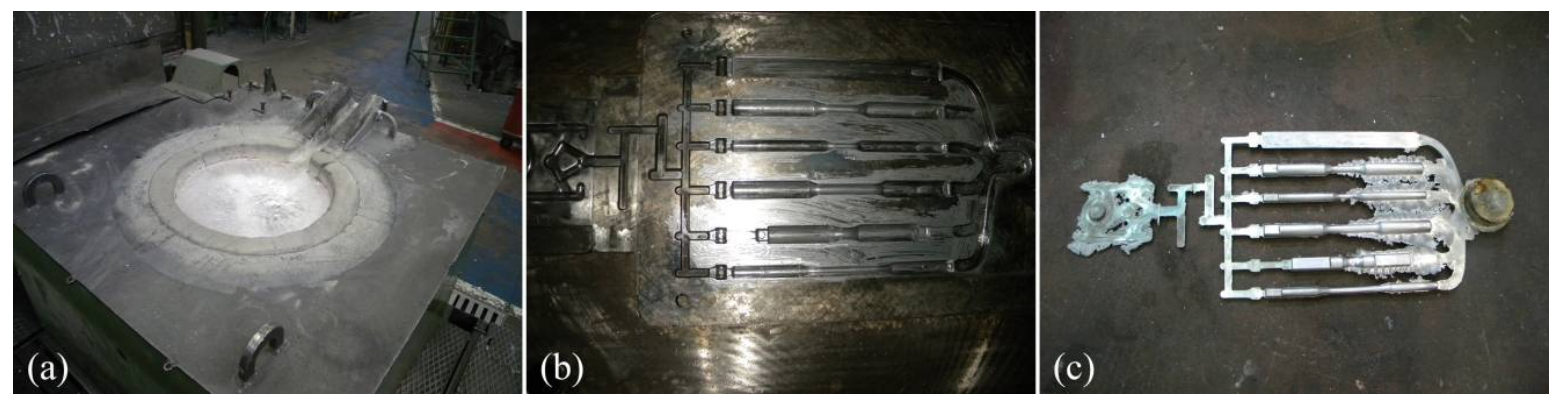

Figure 3. Manufacturing process for specimens made from the AlSi9Cu3 alloy. (a) Melt preparation; (b) multi-cavity mold-form; (c) pressure die casting part.

A common feature of all the specimens in Figure 2 is that the macro porosity is concentrated in the middle of the specimen along its longitudinal axis—see also Figure $9 \mathrm{~d}$. According to the research of Murakami and Endo [24] such a distribution of macro pores is less detrimental to the fatigue life. In Figure 4 the critical cross-sections that correspond to the fatigue failures of the seven specimens in Figure 2 are presented-see Section 2.3 for details. If the material was ductile the necked and cracked material would have been oriented at an angle of approximately $45^{\circ}$ relative to the axis of loading. In contrast, the cracked surface is almost perpendicular to the axis of loading and the two opposite parts fit very well to each other. This means that the failure was brittle, with almost no plastic flow of the material, even on the mezzo scale.

The porosity, which arises because of expelled gases from the melted alloy, is often composed of regular-shaped voids, i.e., spherical or elliptical pores [7] that enable easy geometrical modelling. Pores with a complex shape usually emerge due to the different density of the material in its liquid/solid state, partial cold shuts or insufficient highpressure, die-casting pressures [7]. These pores are flat with irregular shapes and are more problematic in terms of crack initiation [21]. In Figure 4 the most disc-like pores correspond 
to Specimens no. 17 and 31. Besides that, a pronounced lamellar brittle structure is present in the middle of Specimen no. 31, but not near its outer surface. The largest pores with more regular shapes can be seen in Specimens no. 12, 16, and 7. Similar, but smaller, pores are also present in Specimens no. 36 and 4. To obtain a geometric distribution of pores inside each of the specimens, a $\mu$-CT scanning was performed for the narrowest part of each specimen from Figures 2 and 4. For this purpose a GE VI tome Ix s 240 device (General Electric, Boston, MA, USA) was applied with a scanning accuracy of $0.002 \mathrm{~mm}$. The raw scanning data was available in *.STL format. Since one of the basic objectives of this research was an exact geometric characterisation of the embedded porosity, the pores should be represented in a more maths-friendly form. The details of the mathematical pore modelling are given in Section 2.2.

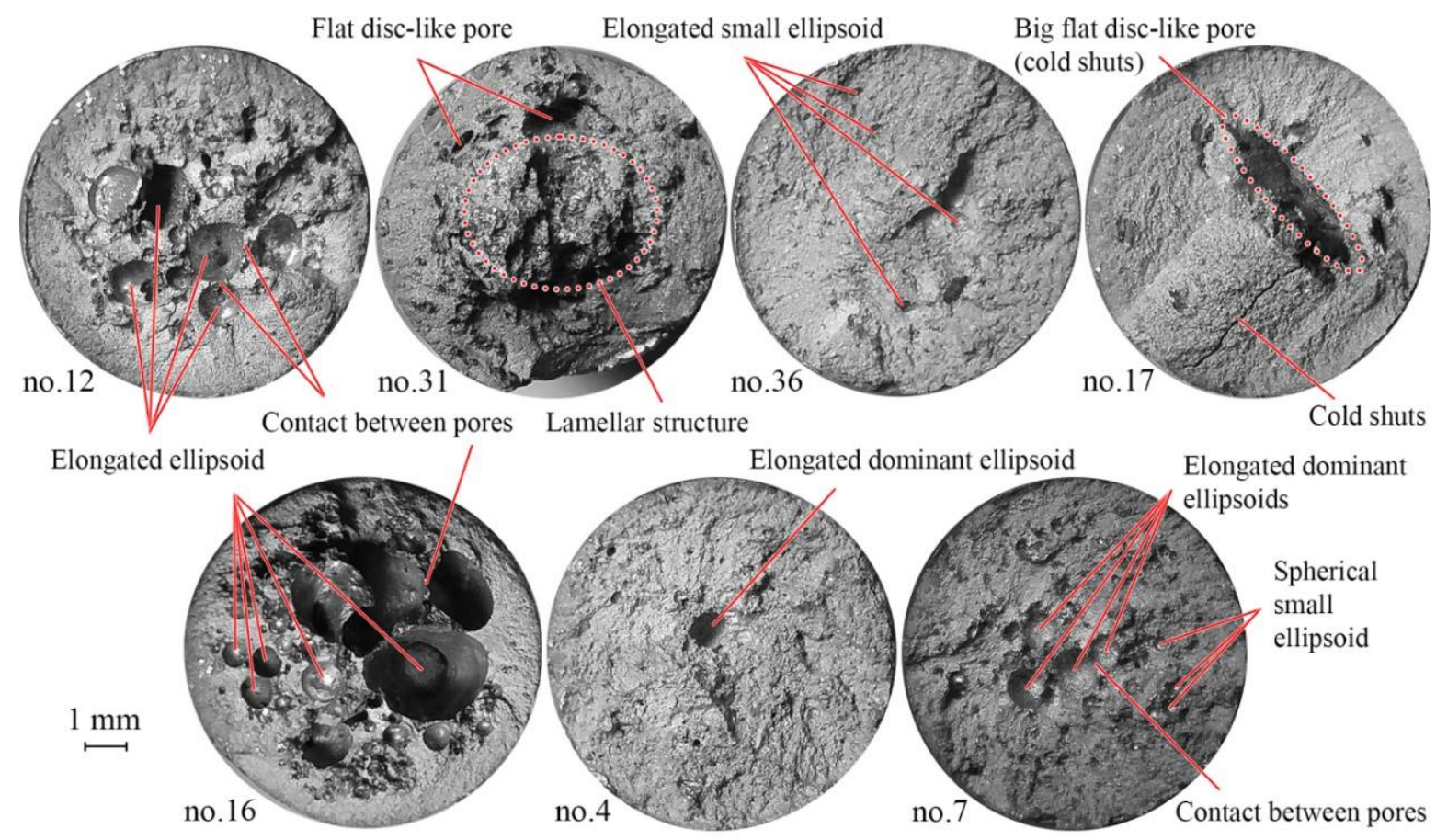

Figure 4. Pores and other inhomogeneities in critical cross-sections; pictures were made using a macro-lens and show fatigue-crack surfaces immediately after the experiment.

\subsection{Geometric Segmentation}

In this subsection we describe the geometric (vector) segmentation method devised to describe a porous material as a collection of ellipsoids. The main idea of this procedure is to extract the idealised pore shapes in the form of ellipsoids from the input data that consists of scanned images in the form of * ${ }^{*}$ stl files of size 100-400 MB. Since the geometry in the *.stl file is composed of many triangles that represent the boundaries of the body and need to be grouped together into the corresponding defects, from which the ellipsoids are finally formed. In this article the segmentation technique was applied to estimate, how different feature-extraction methods (as opposed to the voxel technique from [21]) influence the efficiency of the geometric characterisation and the quality of the predicted fatigue lives. The segmentation process can be divided into two consecutive parts:

1. The topological part in which the input data are processed and expressed as a collection of triangulated surfaces.

2. The numerical-analytic part, in which each of the surfaces is approximated by a suitable ellipsoid. 
Topological part: The input data consist of a vast number of triangles that describe the boundaries of the pores. The first step is to cluster these triangles into triangulations of closed connected surfaces (see [25] for some background on surfaces). In the ideal case, each edge of such a triangulation should appear in exactly two triangles, and the triangles should intersect only along common edges. However, this is not always the case due to inconsistencies in the input data that motivate several clearing interventions. The inconsistency-clearing process is an essential building block of the topological part, which is difficult to find in the existing textbooks. The innovative elements of this inconsistency clearing are represented by the following steps:

(a) We first find triangles that have an edge that is not shared by any other triangle. We inductively remove such triangles, assuming they appear as noise in the scanning process. In a single inductive thread, we remove up to nine triangles. If a procedure of this sort were to remove more triangles in a single thread, the entire thread of triangles would be kept as it is. The idea is to remove small clusters of such triangles (noise). On the other hand, we want to keep large components, where the omission of a triangle (a local anomaly in the data) along with the unrestricted removal would eliminate the component, while the numerical computations on the locally anomalous raw-data component still provide us with a good approximation. It turns out that this does not significantly change the input data, i.e., such triangles appear in small regions. This observation gives credibility to the assumption that such a modification does not significantly affect the final result.

(b) We partition the remaining triangles into connected components using the underlying graph induced by the edges of the triangles.

(c) It turns out that in some cases the obtained components still do not represent a combinatorial surface. For example, a component can represent two surfaces connected by a few individual triangles. In such cases the deviating triangles are removed, and the components adjusted.

(d) The obtained components can be assumed to be triangulations of closed connected surfaces. In practice it turns out that a few deficiencies remain, but they are assumed to be negligible or have no effect on further procedures in the numerical-analytical part. For example, different triangles might intersect (see Figure 5), with the sheer number of triangles making the prevention of such occurrences computationally unfeasible. In Figure 5 the enclosed space is the union of three tetrahedrons. The component itself is not a proper triangulation of its boundary as some of the triangles intersect. However, the component can still be oriented and thus the conclusions of the numerical-analytical part still hold and provide the appropriate ellipsoid. For example, the quantity $\mathrm{V}$ computed for such a pore is still equal to its volume, which means that the obtained topological triangulations seem to visually approximate the porous material well.

(e) At the end, the triangles in each component are oriented consistently (see [26] for details of the orientation), which is required for the application of the formulas in the numerical-analytical part.

The obtained components consist of up to hundreds of thousands of triangles, with the largest one in our sample having over a million of triangles. In the process we removed between $0.5 \%$ and $0.05 \%$ of the triangles, a negligible quantity.

Numerical-analytical part: In this part we consider that each surface component obtained in the topological part encloses a three-dimensional pore. We approximate each pore with a unique solid ellipsoid with the same first and second momentum as the pore and use the difference in the zero-momenta (i.e., volumes) to estimate the obtained fit. See $[27,28]$ for the background on momenta and [29] for a related approach. A related inertia ellipsoid is unsuitable for our purposes as, amongst other issues, not every ellipsoid 
can represent an inertia ellipsoid, see p. 219 of [29]. Given a three-dimensional solid $A$, let $d V$ denote the infinitesimal volume element. Then:

- The zero momentum is the volume $\int_{A} d V$.

- The first momentum is the geometric centre of $A$, expressed as $x^{*}=\int_{A} x d V$

- The sec ond momentum is the matrix $J=\int_{A}\left(x-x^{*}\right)\left(x-x^{*}\right)^{T} d V$

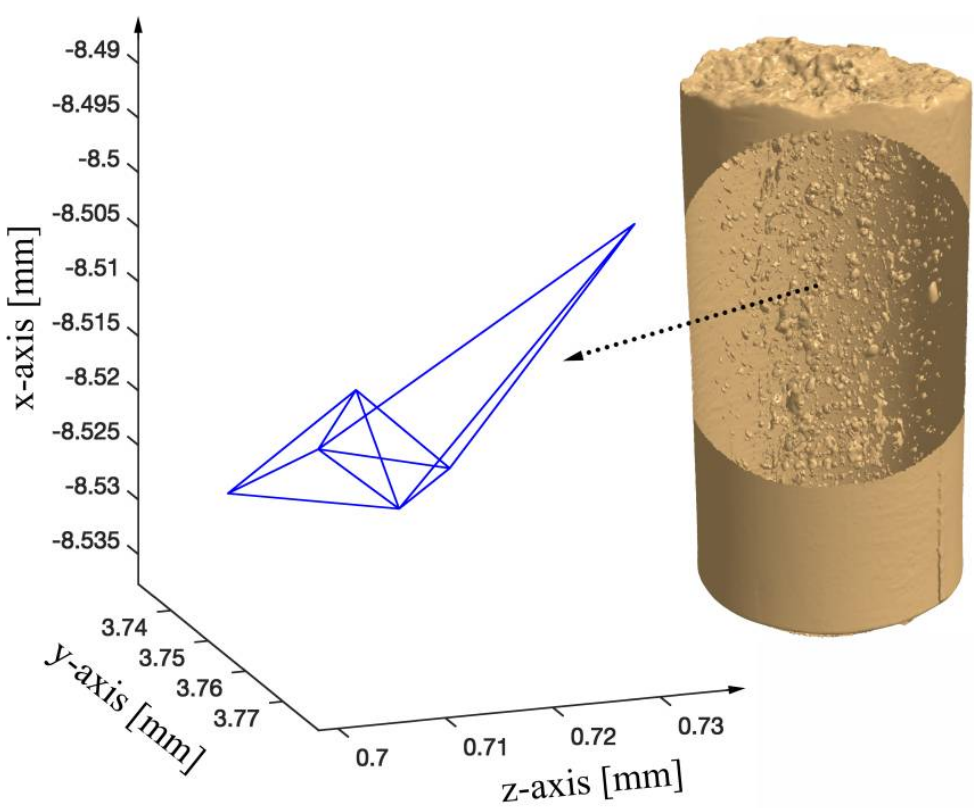

Figure 5. Component obtained in the topological part: an example of an ill-conditioned geometry due to the intersection of triangles, which should represent an outer boundary of the pore.

If $A$ was of volume 1 , and thus $d V$ represented a uniform probability distribution on $A$, the first and second momenta would represent the average and the covariance matrix. The strategy of fitting the first and second momenta while using the volume as a quality-of-fitting estimator makes mathematical as well as practical sense. Especially for non-convex pores, approximations with ellipsoids of the same volume appear to be inferior to the one devised above. Furthermore, ellipsoids are solids of maximum volume with the prescribed first and second momenta, meaning that the ratio between the volumes of the approximating pore and of the fitted ellipsoid is always below or equal to 1 .

Numerically, the fitting is only performed using linear algebra. If $S$ is a component obtained in the first part (i.e., a collection of oriented triangles in the space), its volume equals $V=\sum_{t \in S} V_{t}$, where

$$
V_{t}=\frac{1}{6}\left|\begin{array}{cc}
a_{t}^{T} & 1 \\
b_{t}^{T} & 1 \\
c_{t}^{T} & 1 \\
p^{T} & 1
\end{array}\right|,
$$

$V_{t}$ is fixed for each oriented triangle $t$ spanned by an oriented triple of vertices $a_{t}, b_{t}, c_{t}$, and $p$. For the sake of numerical stability, we choose $p$ to be the average of all the points appearing in $S$. The geometric centre $x^{*}$ of $S$ is now obtained as the weighted average 
of the geometric centres of the triangles $x^{*}=\sum_{t \in S} \frac{V_{t}}{V} \frac{a_{t}+b_{t}+c_{t}}{3}$, and this is the centre of the approximating ellipsoid. The second momentum is computed as:

$$
\begin{gathered}
J=\sum_{t \in S} \frac{V_{t}}{V} M_{t}^{T} \frac{1}{20}\left[\begin{array}{llll}
2 & 1 & 1 & 1 \\
1 & 2 & 1 & 1 \\
1 & 1 & 2 & 1 \\
1 & 1 & 1 & 2
\end{array}\right] M_{t} \\
M=\left[\begin{array}{ll}
a_{t}^{T} & 1 \\
b_{t}^{T} & 1 \\
c_{t}^{T} & 1 \\
p^{T} & 1
\end{array}\right] .
\end{gathered}
$$

The eigenvectors and eigenvalues of $J$ are the axes of symmetry and corresponding radii of the approximating ellipsoid. Three examples of the fitted ellipsoids are presented in Figure 6.

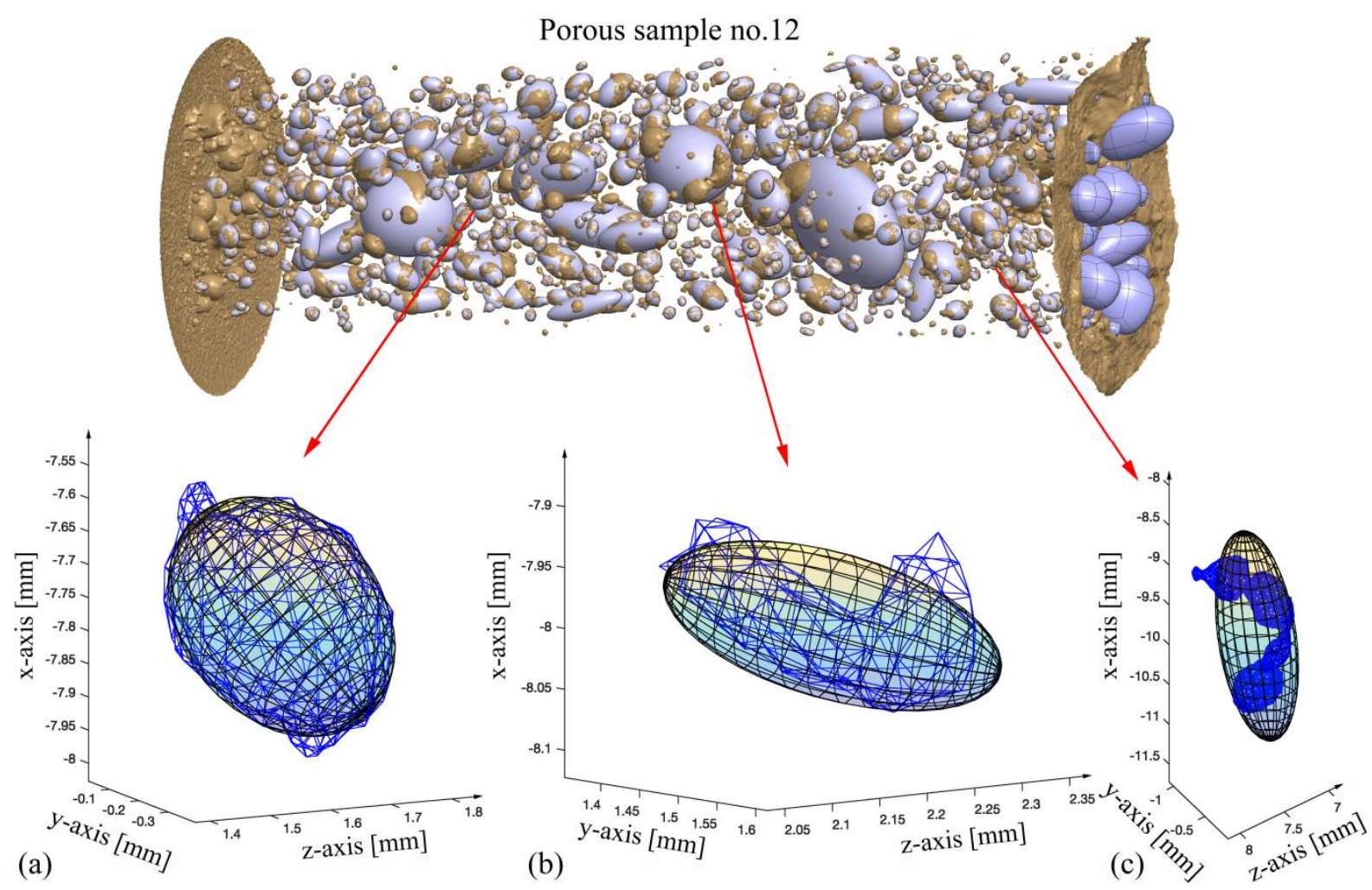

Figure 6. A comparison of the $\mu$-CT scan and the extracted ellipsoids for the Specimen no. 12 (above); three examples of the fitted ellipsoids with different goodness-of-fit (below). (a) High fitting; (b) medium fitting; (c) low fitting.

The ellipsoidal pores can achieve a high fitting percentage, e.g., up to $98 \%$. Such an example is presented on the left-hand side of Figure 6. The more the shape of the pore deviates, the lower the fitting percentage, with the extreme case being the one on the right-hand side of Figure 6 with only a 27\% fit. From this picture it seems that the latter ellipsoid poorly represents the segmented pores. The reason for this lies in the method of calculating the ellipsoid radii. Since they are determined based on the second momentum, the clustered segments at both ends inflate the diagonal terms of the matrix $J$, thus resulting in an extended ellipsoid. In this case a much better approximation of the pores would be with two ellipsoids positioned in the form of the letter V. However, this is impossible to achieve with the presented segmentation methodology unless an additional pre-processing 
of the segments is applied. Nevertheless, the basic geometric properties (i.e., the centre of gravity, the volume and the volumetric second momentum for the extracted material) should be well encoded in the ellipsoids. When modelling the porosity, a trade-off should be made between the accuracy of the geometric characterisation and, the meshing ability of the FE model and the resulting CPU time for the numerical analyses. On the basis of the preliminary test the minimum threshold value for the ellipsoid half-axles was $0.01 \mathrm{~mm}$. All the pores which had all the three half-axes smaller than this threshold values were discarded. For example: for the Specimen no. 12 (see the top of Figure 6 and Table 3) 818 ellipsoids were generated, which accounts for approximately half of the detected ellipsoids from the CT scans.

Table 3. Summary of the fitting values for the seven specimens.

\begin{tabular}{ccccc}
\hline Sample & Mean Fit & Median Fit & Standard Deviation of a Fit & Number of Pores \\
\hline No. 4 & 0.868 & 0.901 & 0.111 & 521 \\
No. 7 & 0.884 & 0.922 & 0.110 & 884 \\
No. 12 & 0.874 & 0.919 & 0.118 & 818 \\
No. 16 & 0.828 & 0.874 & 0.149 & 837 \\
No. 17 & 0.705 & 0.718 & 0.149 & 55 \\
No. 31 & 0.783 & 0.812 & 0.146 & 627 \\
No. 36 & 0.846 & 0.884 & 0.125 & 455 \\
\hline
\end{tabular}

A goodness-of-fit between the ellipsoids and the clustered segments is represented in Figure 7 with the fitting diagrams. It should be noted, however, that the fitting diagrams encode the degree to which the pores deviate from the ellipsoidal form, rather than a deficiency in our fitting approach. The horizontal lines appearing in each of the diagrams at fit 0.63 correspond to approximations of the tetrahedral holes (i.e., holes, bounded by four triangles). For such holes, the fitting ratio is constant. From the diagrams we see that larger pores typically have a better fit, i.e., the approximations with ellipsoids typically closer to the pores, although each sample contains large pores with a poor fit. The mathematical and physical justifications of the numerical-analytical part encourage a reasonable belief that the physical properties of the pores are nonetheless encoded in the obtained ellipsoids to the greatest possible extent. Figure 8 represents a statistical distribution of fitting values and Table 3 summarizes the results and various aspects of our fitting procedure. The histograms in Figure 8 demonstrate that for most samples, the largest proportion of holes can be approximated well (fit above 90\%). The obvious exception is Specimens no. 17, which eventually yields the worst comparison with the voxel technique. The spikes appearing in each of the histograms at fit 0.63 correspond to approximations of tetrahedral holes. In Table 3 some data on the obtained approximation by ellipsoids are presented. As before, the fit of a hole is the quotient between the volume of the hole and the volume of the approximating ellipsoid. We see that the worst fit is obtained for sample no. 17, which coincides with the largest deviation compared to the voxel technique. 
The following applies to the relationship:

$\frac{\text { volume of a hole }}{\text { volume of the approximating ellipsoid }} \leq 1[/]$
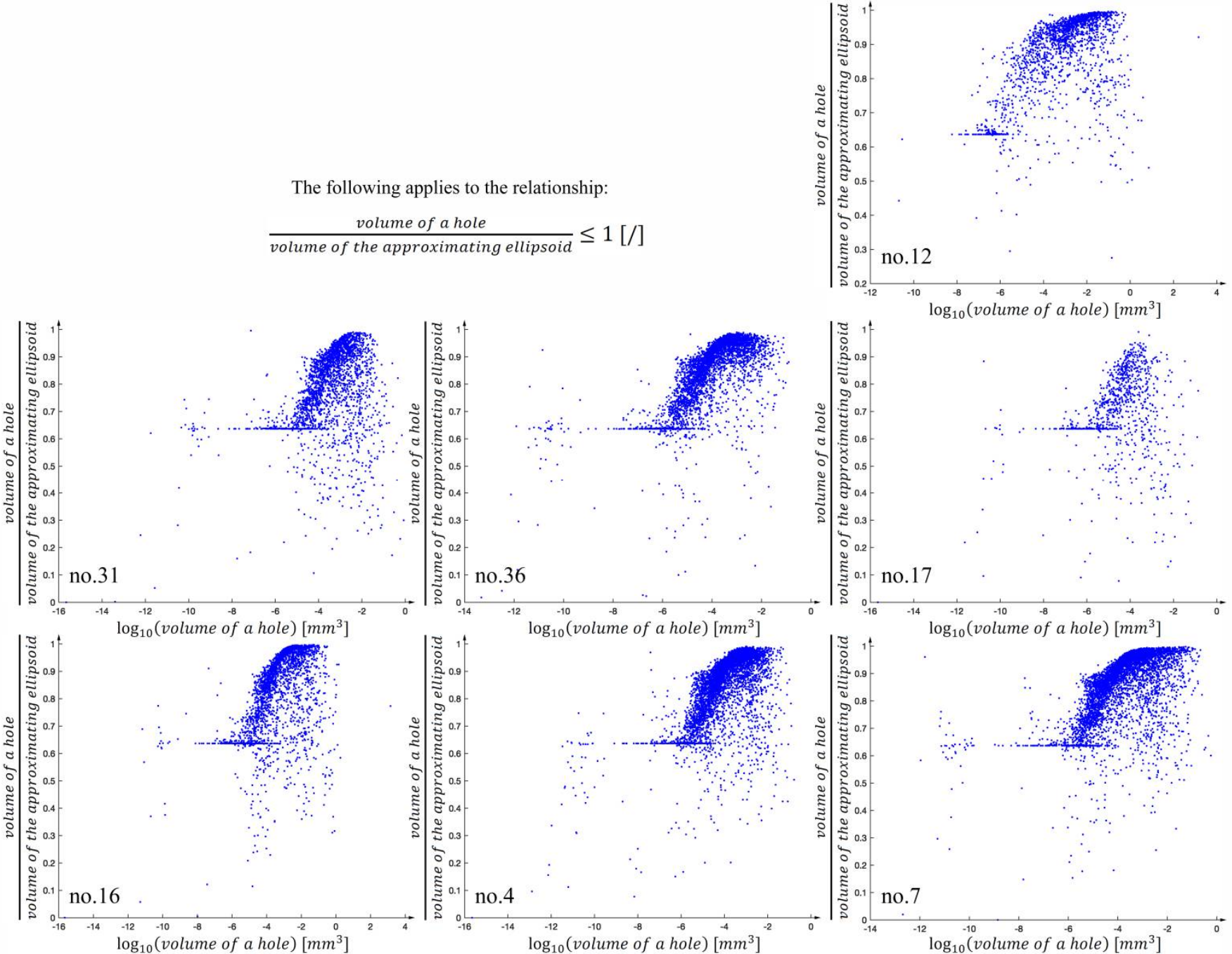

Figure 7. Fitting diagrams that show a ratio between the actual segment volume and the volume that was approximated by the ellipsoid with the same volumetric second moments.

After the segmentation process was finished the extracted ellipsoids were included as pores into the 3D model of the critical cylindrical cross section of the specimen. For this purpose, a CATIA V5 macro was used. Each pore individually was first modelled with a sphere and centred at the corresponding geometric position. Then it was converted into the 3D ellipsoid using the affine transformations in the 3D modeller. Finally, the ellipsoid was oriented in the space with rotational transformations. The latter was necessary to achieve the proper notch effects of the individual pores. The corresponding *.CATPart file was then imported into Abaqus software. 

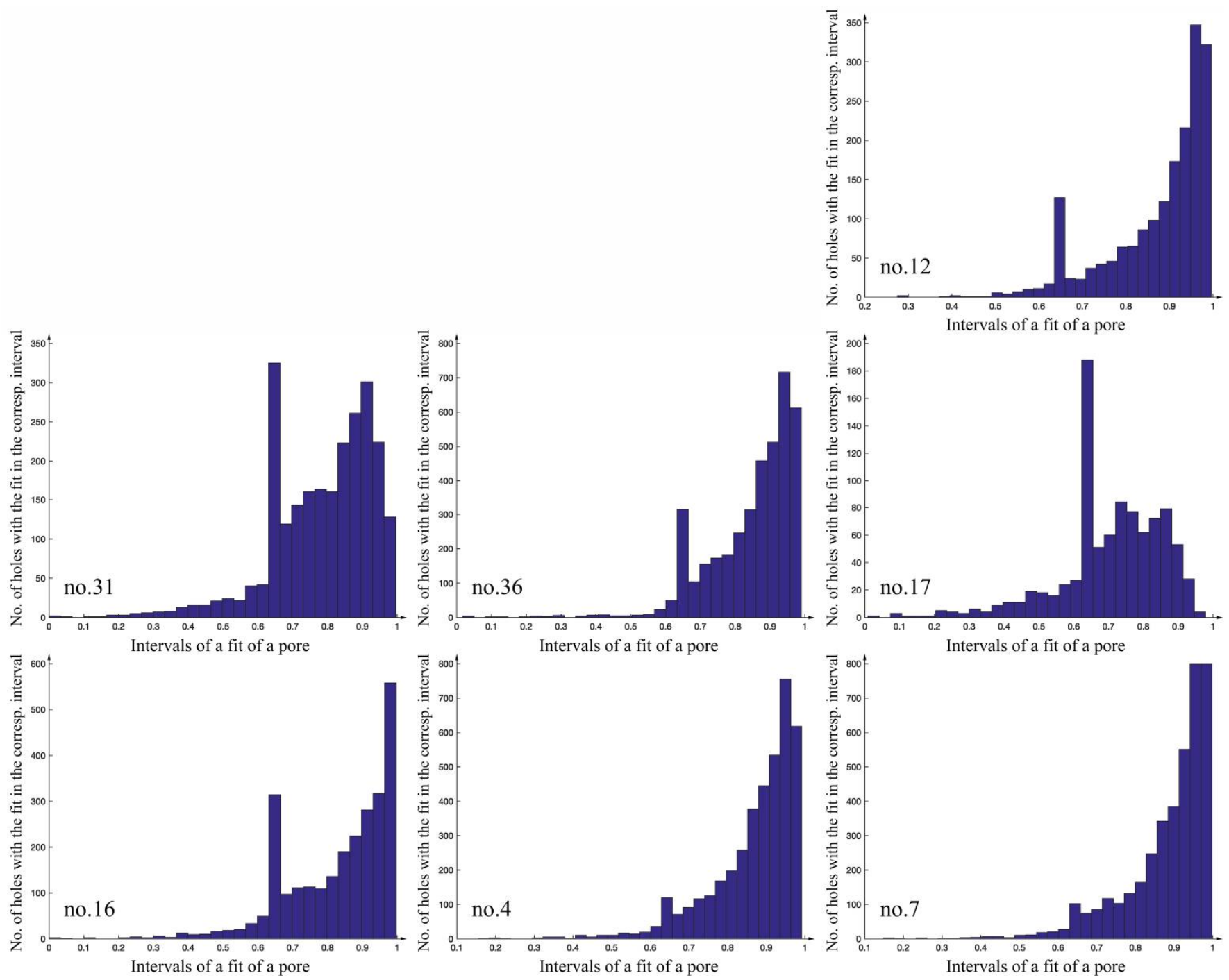

Figure 8. Statistical distribution of fitting values: relative frequencies of the ratio between the segmented volume and the volume of the corresponding fitted ellipsoid.

\subsection{Experimental-Numerical Approach for Analysing the Fatigue Life}

The experimental and numerical fatigue-life estimation was based on a strain-controlled approach [30,31]. In this manner a partial plastification of the critical cross-section of the specimen is not just allowed, but also expected in our case due to the significant presence of voids throughout the whole specimen. Consequently, a relatively small number of the loading cycles to failure is expected, which means that the low-cycle fatigue (LCF) domains that were considered in our case [32]. The experimental set-up of the LCF experiments is presented in Figure 9a.

The LCF experiments were performed on an MTS Landmark servo-hydraulic testing machine with a $250 \mathrm{kN}$ force range. Fully reversal $(R=-1)$ sinusoidal loading cycles of constant strain amplitudes were strain controlled according to a signal from a mechanical extensometer that was mounted to the middle thinnest part of the specimens. The applied extensometer was MTS 632.53F-14 with a gauge length of $l_{0}=12 \mathrm{~mm}$. According to the output of the extensometer a displacement of the servo-hydraulic machine was determined as follows:

$$
\varepsilon_{a}=\frac{ \pm \Delta l}{l_{0}} \text {, i.e. : } \pm \Delta l=\varepsilon_{a} \cdot l_{0} .
$$


The corresponding displacements $\pm \Delta l$ from Equation (7) for the pre-set strain amplitudes are listed in Table 4 together with the experimentally determined and numerically estimated fatigue lives for each of the seven specimens. For each specimen, its porosity share is also listed in Table 4 . The applied strain amplitudes were in the range $0.15 \%$ to $0.3 \%$. They were determined on the basis of static tensile tests of the porous specimens, as described in Tomazincic et al. [21]. The strain-controlled dynamic loading results in significant local stress concentrations $\sigma_{i}$ at the boundaries of the dominant macro pores that reduce the fatigue life of the porous specimen. These notch effects are estimated by applying the FEM simulations to the specimen FE models with the reconstructed porositysee Figure $9 \mathrm{~d}$. The stress-strain distribution $\sigma_{i}-\varepsilon_{i}$ through the specimen cross-section is calculated on the basis of the cyclic curve for the homogeneous alloy AlSi9Cu3 [9], which is presented in Figure 9b. Finally, this numerical result can be applied to numerically estimate the fatigue life $N_{i}$ of the specimen by considering the Coffin-Manson curve of the homogeneous material—see Figure 9c.

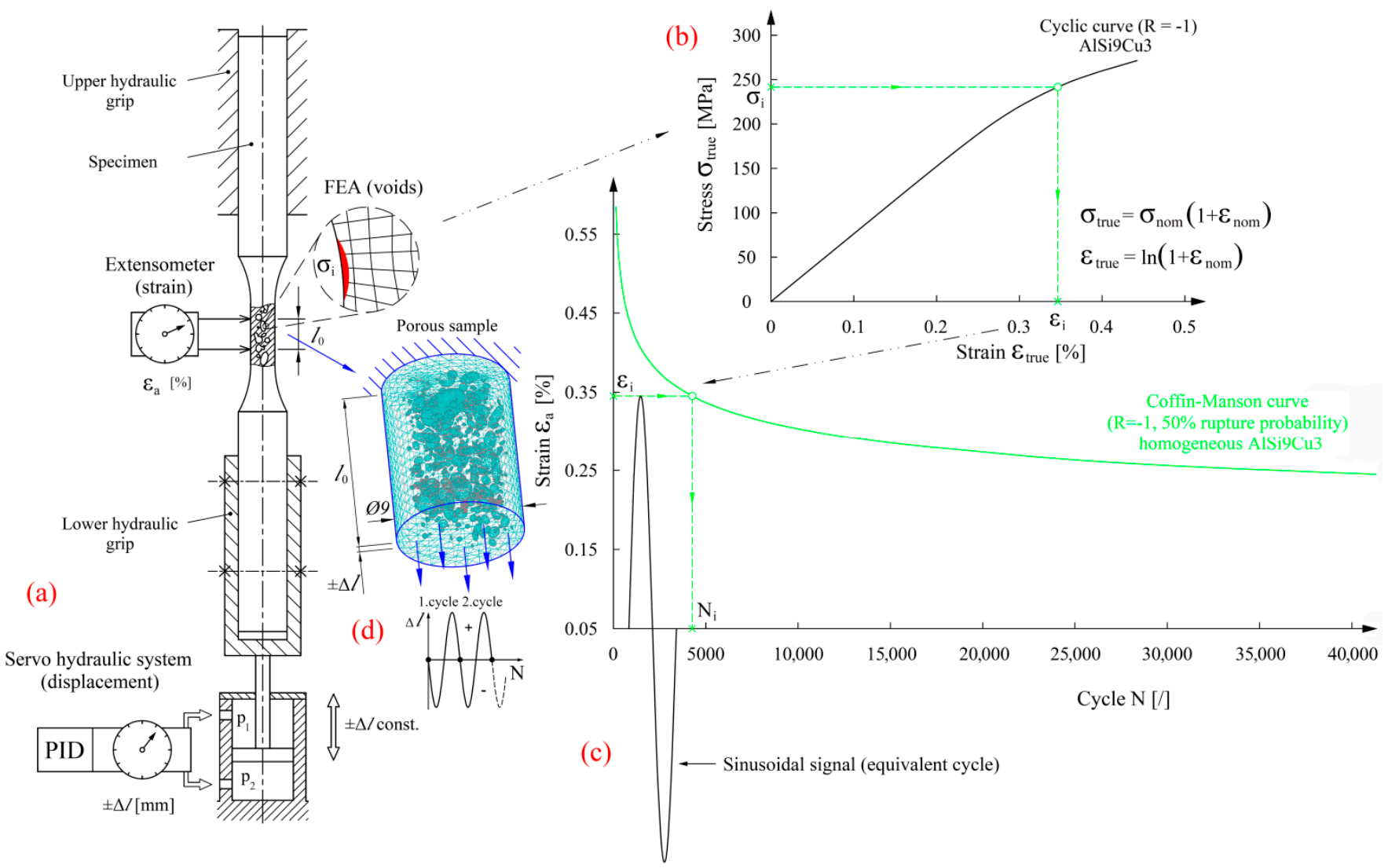

Figure 9. Experimental-numerical evaluation of the fatigue life for the porous AlSi9Cu3 alloy. (a) Low-cycle fatigue testing; (b) cyclic curve-no. 12; (c) Coffin-Manson relation-no. 12; (d) porous sample no. 12 for FEM. 
Table 4. Experimentally determined and numerically estimated fatigue lives for AlSi9Cu3 porous specimens.

\begin{tabular}{|c|c|c|c|c|c|c|c|c|}
\hline \multirow{2}{*}{$\begin{array}{l}\text { Spec. } \\
\text { no. }\end{array}$} & \multirow{2}{*}{$\begin{array}{c}\text { Nominal Strain } \\
\varepsilon_{a}(\%)\end{array}$} & \multirow{2}{*}{$\begin{array}{c} \pm \Delta l \\
(\mathrm{~mm})\end{array}$} & \multirow{2}{*}{$\begin{array}{l}\text { Porosity } p \\
\text { (/) [21] }\end{array}$} & \multicolumn{2}{|c|}{$N_{\text {calc, voxel technique }}[21]$} & \multicolumn{2}{|c|}{$N_{\text {calc, geom. segmentation technique }}$} & \multirow{2}{*}{$N_{\exp }[21]$} \\
\hline & & & & $N_{1 . i t e r}(/)$ & $N_{2 . i t e r}(/)$ & $N_{1 . i t e r}(/)$ & $N_{2 . \text { iter }}(/)$ & \\
\hline \multirow{2}{*}{31} & \multirow{2}{*}{0.15} & \multirow{2}{*}{0.018} & \multirow{2}{*}{0.0205} & 741 & 1315 & 741 & 1358 & \multirow{2}{*}{1853} \\
\hline & & & & \multicolumn{2}{|c|}{2056 (sum $\left.N_{1,2 . \text { iter }}\right)$} & \multicolumn{2}{|c|}{2099 (sum $\left.N_{1,2 . \text { iter }}\right)$} & \\
\hline \multirow{2}{*}{36} & \multirow{2}{*}{0.17} & \multirow{2}{*}{0.0204} & \multirow{2}{*}{0.0051} & 18,543 & 3873 & 18,553 & 1629 & \multirow{2}{*}{48,619} \\
\hline & & & & \multicolumn{2}{|c|}{ 22,416 (sum $\left.N_{1,2 . \text { iter }}\right)$} & \multicolumn{2}{|c|}{ 20,182 (sum $\left.N_{1,2 . \text { iter }}\right)$} & \\
\hline \multirow{2}{*}{12} & \multirow{2}{*}{0.2} & \multirow{2}{*}{0.024} & \multirow{2}{*}{0.0569} & 1695 & 1656 & 1695 & 2223 & \multirow{2}{*}{4243} \\
\hline & & & & \multicolumn{2}{|c|}{3351 (sum $\left.N_{1,2 . \text { iter }}\right)$} & \multicolumn{2}{|c|}{3918 (sum $\left.N_{1,2 . \text { iter }}\right)$} & \\
\hline \multirow{2}{*}{17} & \multirow{2}{*}{0.22} & \multirow{2}{*}{0.0264} & \multirow{2}{*}{0.024} & 52 & 54 & 714 & 421 & \multirow{2}{*}{98} \\
\hline & & & & \multicolumn{2}{|c|}{106 (sum $\left.N_{1,2 . \text { iter }}\right)$} & \multicolumn{2}{|c|}{1135 (sum $N_{1,2 . \text { iter }}$ ) } & \\
\hline \multirow{2}{*}{16} & \multirow{2}{*}{0.25} & & & 114 & 228 & 114 & 497 & \\
\hline & & 0.03 & 0.0812 & $342(s u$ & $\left.J_{1,2 . \text { iter }}\right)$ & $611(s u$ & $\left.\mathrm{V}_{1,2 . \text { iter }}\right)$ & 282 \\
\hline & & & & 278 & 258 & 303 & 355 & \\
\hline 4 & 0.3 & 0.036 & 0.0062 & $536(s u$ & $\left.J_{1,2 . \text { iter }}\right)$ & $658(s u$ & $\left.\mathrm{V}_{1,2 . \text { iter }}\right)$ & $3 / 0$ \\
\hline 7 & $0 ?$ & $0 \Omega 26$ & 0 & 167 & 417 & 270 & 335 & 415 \\
\hline 7 & 0.3 & 0.036 & 0.0212 & $584(s u$ & $\left.I_{1,2 . \text { iter }}\right)$ & $605(s u$ & $\left.\mathrm{V}_{1,2 . \text { iter }}\right)$ & 415 \\
\hline
\end{tabular}

Numerical simulations were carried out for the most critical part of the specimen (i.e., its thinnest part to which the extensometer was mounted—see Figure 9d) using the Abaqus-Standard (implicit) analysis [33]. The exact nominal strains in this part were known from the experiments. The porous structure was modelled by introducing elliptical voids to the solid parts. The ellipsoid geometries were determined according to the procedure described in Section 2.2. The porous 3D model was meshed with C3D4 tetrahedron finite elements with an element edge length of $0.2 \mathrm{~mm}$ at the pore boundaries. 3D CAD models were partitioned to 16 partitions before the meshing took place. The mesh seeds were defined at the pore boundaries to assure the acceptable mesh quality around the notches. Automatic free-meshing technique was applied to obtain the FE models. The same settings for meshing the porous models were applied in our previous research [21], where the pores were identified and isolated using the voxel technique. Table 5 provides details of the finite-element models for the individual specimens for both approaches to the geometric characterisation of porosity, the voxel- and vector-segmentation techniques.

Table 5. FE-model sizes for different specimens.

\begin{tabular}{ccccc}
\hline \multirow{2}{*}{$\begin{array}{c}\text { No. } \\
\text { Spec. }\end{array}$} & \multicolumn{2}{c}{ Voxel Based Technique } & \multicolumn{2}{c}{ Vector-Segmentation Based Technique } \\
\cline { 2 - 5 } & No. of Finite Elements & No. of Nodes & No. of Finite Elements & No. of Nodes \\
\hline 31 & $1,418,333$ & 243,369 & 981,430 & 167,600 \\
36 & 565,482 & 96,870 & 423,343 & 73,025 \\
12 & 890,641 & 155,848 & 912,779 & 159,618 \\
17 & 120,384 & 23,171 & 322,189 & 55,696 \\
16 & 903,091 & 157,681 & 877,352 & 152,760 \\
4 & 775,910 & 133,187 & 490,349 & 85,862 \\
7 & $1,053,235$ & 180,112 & $1,341,382$ & 228,381 \\
\hline
\end{tabular}

For each of the seven porous specimens, the numerical prediction of the fatigue life is based on simulating the stress-strain response for the reversal points of the two consecutive fully reversal loading cycles-see Figure $9 \mathrm{~d}$. The basic material properties for this aluminium alloy are: a Poisson's ratio equal to 0.33 , a mass density of $2.76 \mathrm{~g} / \mathrm{cm}^{3}$ and a Young's modulus of 79,631 MPa [21]. The nonlinear behaviour of the material is 
modelled with an average cyclic curve for the pore-free homogeneous AlSi9Cu3 alloy that was determined from the fully reversal strain-controlled experiments in the previous research [9]. The parameters of the Ramberg-Osgood model for this cyclic curve $(R=-1)$ in equation (8) are the cyclic strain hardening exponent $n^{\prime}=0.0979$ and the cyclic strength coefficient $K^{\prime}=542 \mathrm{MPa}$ :

$$
\varepsilon=\frac{\sigma}{E}+\left(\frac{\sigma}{K^{\prime}}\right)^{\frac{1}{n^{\prime}}}
$$

The true-stress/true-strain cyclic curve was introduced into the Abaqus software as a multi-linear kinematic hardening material model that is the solver's best approximation of the Bauschinger material behaviour [12]. The cylindrical model with voids is supported on one side and loaded with a prescribed displacement $\pm \Delta l$ on the other side. The displacement amplitude $\Delta l$ is the same as was applied during the experiments-see Table 4 . The stress-strain distributions from the two reversal points of the second loading cycle are applied for the fatigue-life prediction.

To predict the fatigue life a SIMULIA fe-safe software module was applied. The same cyclic curve as before was applied in a combination with the Coffin-Manson curve for the homogeneous alloy AlSi9Cu3 [34,35]:

$$
\frac{\Delta \varepsilon}{2}=\frac{\sigma \prime_{f}}{E}\left(2 N_{f}\right)^{b}+\varepsilon \prime_{f}\left(2 N_{f}\right)^{c}
$$

The parameters of the Coffin-Manson curve $(R=-1)$ for a $50 \%$ probability of failure, which were determined before [9], are as follows: $\sigma_{f}^{\prime}=1087 \mathrm{MPa}, \varepsilon_{f}^{\prime}=0.0001, b=-0.152$ and $c=-1.605$ (see also Figure 9c). The surface roughness was considered via the surfaceroughness factor $\kappa_{t}=1.02$ [36]. Elemental solutions for the stress and strain tensors were taken as relevant for calculating the fatigue life. The fatigue life was calculated in an iterative manner. In each iteration the elemental fatigue damage was calculated by combining the critical-plane approach with a Brown-Miller-Morrow (BMM) model [36,37]:

$$
\frac{\Delta \gamma}{2}+\frac{\Delta \varepsilon_{\mathrm{n}}}{2}=1.65 \frac{\left(\sigma \prime_{\mathrm{f}}-\sigma_{\mathrm{m}}\right)}{\mathrm{E}}\left(2 \mathrm{~N}_{f}\right)^{b}+1.75 \varepsilon I_{f}\left(2 \mathrm{~N}_{f}\right)^{c}
$$

Next, the most critically damaged finite elements were removed, the corresponding fatigue damage was stored, and the modified FE mesh is ready for the next iteration of the fatigue-damage calculation. The fatigue-damage calculation was done for the complete FE models. Then the most critical spot was found on the basis of the smallest calculated fatigue-life. To enable the finite-element annihilation a damage parameter $D$ was defined. The critical damage is when the damage parameter is equal to $D=1$, which is linked to the finite elements with the smallest number of load cycles to failure. In our case the critical damage was always between the pores inside the porous specimens which resulted in inter-pore crack propagation.

In this way the Palmgren-Miner rule was actually applied in the form of finite-element annihilation process-see Figure 10 . The final fatigue life of the porous specimen $N_{\text {porous }}$ [21] was determined as a sum of the stored load-cycles-to-failure $N_{i . i t e r}$. from the consecutive iterations $i=1,2$, etc.:

$$
N_{\text {porous }}=N_{f}=N_{1 . i t e r .}+N_{2 . i t e r .}+\ldots=\frac{1}{D_{1 . i t e r .}}+\frac{1}{D_{2 . i t e r .}}+\ldots
$$

The finite elements were annihilated, when their damage was equal to $D=1$. It turned out the most important was the $1^{\text {st }}$ iteration, because it resulted in annihilation of the finite elements at the thinnest walls between the pores. After the finite elements were deleted, the $2^{\text {nd }}$ iteration followed by new simulation of the stress-strain distribution and the fatigue damage calculation. The fatigue damage from the $2^{\text {nd }}$ iteration was added to the fatigue damage from the $1^{\text {st }}$ iteration for the remaining finite elements. The criterion for further element annihilation was the same, i.e., $D=1$. 


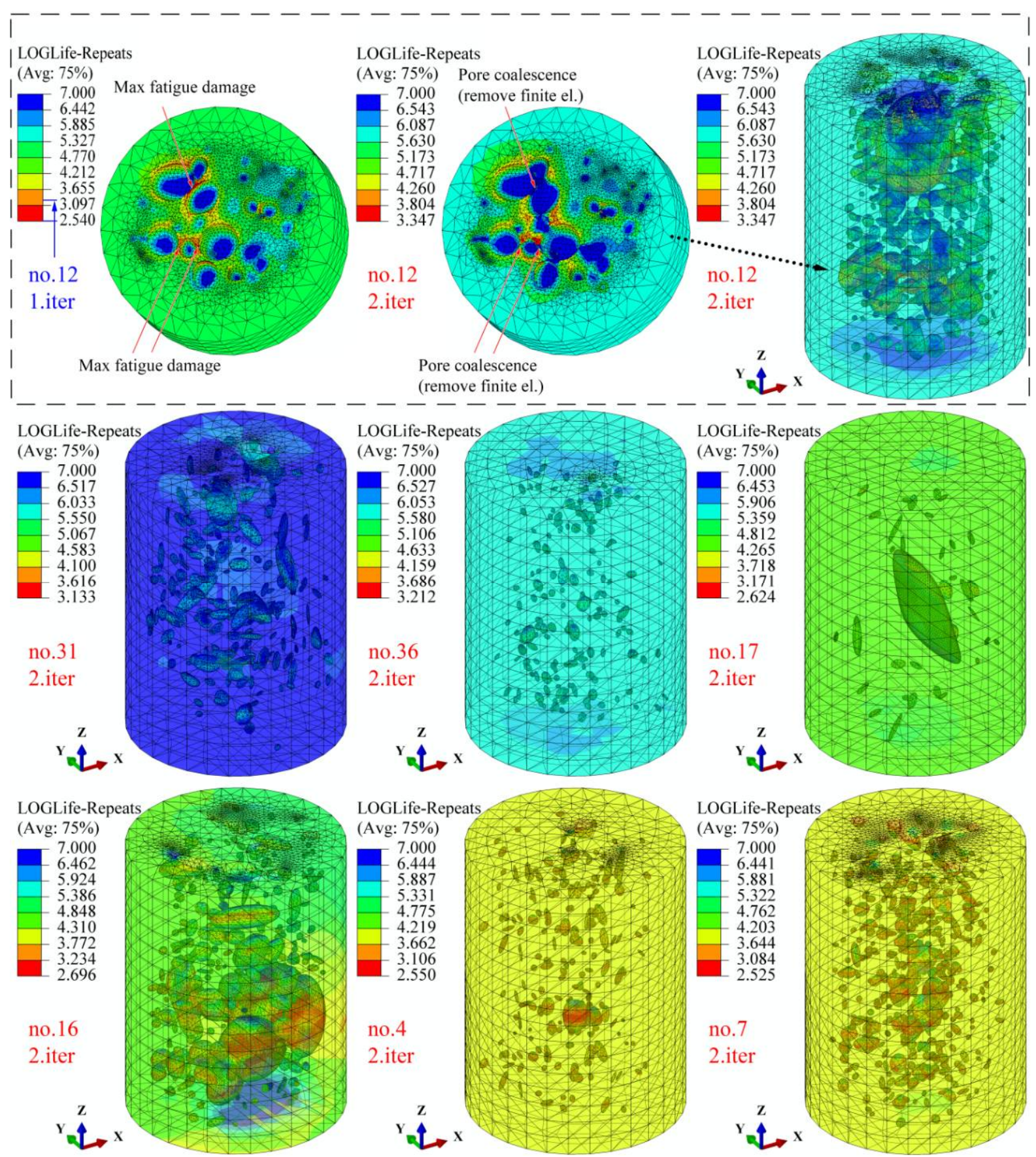

Figure 10. Calculated fatigue lives (in the form of LOGLife) for porous specimens using the Brown-Miller (Morrow) model.

\section{Results}

The numerically predicted fatigue lives in the form of the number-of-load-cycles-tofailure $N_{f}$ are presented in Table 4 together with the experimental results. The corresponding LOGlife values are presented in Figure 10. Besides that, an iterative procedure (two iterations) for calculating the fatigue life is presented at the top of Figure 10 for Specimen no. 12.

In all of the cases the fatigue lives were calculated with two iterations. This is because all the specimens had a lot of closely positioned dominant pores. Therefore, the most critical part of the specimen for the fatigue-crack growth was a thin wall that separated the nearby pores. To remove the most critical finite elements, the criterion was not the highest 
singular peak of the fatigue damage, but the most critical area with a wider spread of the high fatigue damage over more than one finite element. After the corresponding finite elements are removed from the model a pore coalescence typically occurs-see Figure 10, Specimen no. 12. In this manner a group of elliptical pores is replaced by one larger irregular pore. This process is referred to as a void growth and coalescence process in the literature [38]. In the next iteration another simulation of the stress-strain distribution was performed in Abaqus and the fatigue-damage calculation in SIMULIA fe-safe. After the pore coalescence process was stopped and the critical fatigue damage started to propagate into the nearby homogeneous material, the iterations were terminated and the cumulative number of loading cycles to failure was determined according to equation (11). In all seven cases this happened after two iterations.

It can be concluded from Table 4 that the calculated fatigue life of 3918 loading cycles to failure is very close to the experimental result of 4243 cycles for the Specimen no. 12. A similar conclusion can be drawn for Specimen no. 31. Despite the predicted fatigue lives for Specimens no. 4 and no. 7, which were loaded with the highest strain amplitude of $0.3 \%$, are not conservative, such a result can be considered as good, because it is within the acceptable limits. For Specimens no. 16, 17, and 36 the predicted fatigue lives deviate more from those experimentally determined. A modelling of the pores and the cold shuts was especially difficult for Specimen no. 17, because its inhomogeneities are often in the form of step-wise cracks. In this case the voxel technique for pore identification and isolation resulted in better fatigue-life predictions. A very conservative estimate of the fatigue life was obtained for Specimen no. 36, but the prediction was similar to the application of the voxel technique. A reasonable conclusion is difficult to draw for this specimen. One of the reasons for such a deviation might lie in the fact that the loading strain amplitude was the smallest, i.e., only $0.17 \%$. This means that the loading was actually in the high-cycle fatigue regime, where the slope of the fatigue-life (Coffin-Manson) curve is steeper. This means that every deviation of the calculated stress-strain response from the actual one can cause a significant difference between the predicted and experimentally determined fatigue lives. The results for the voxel- and vector-segmentation techniques are presented in Figure 11. It can be concluded from this figure that significant differences in the fatigue-life predictions were obtained only for Specimen no. 17.

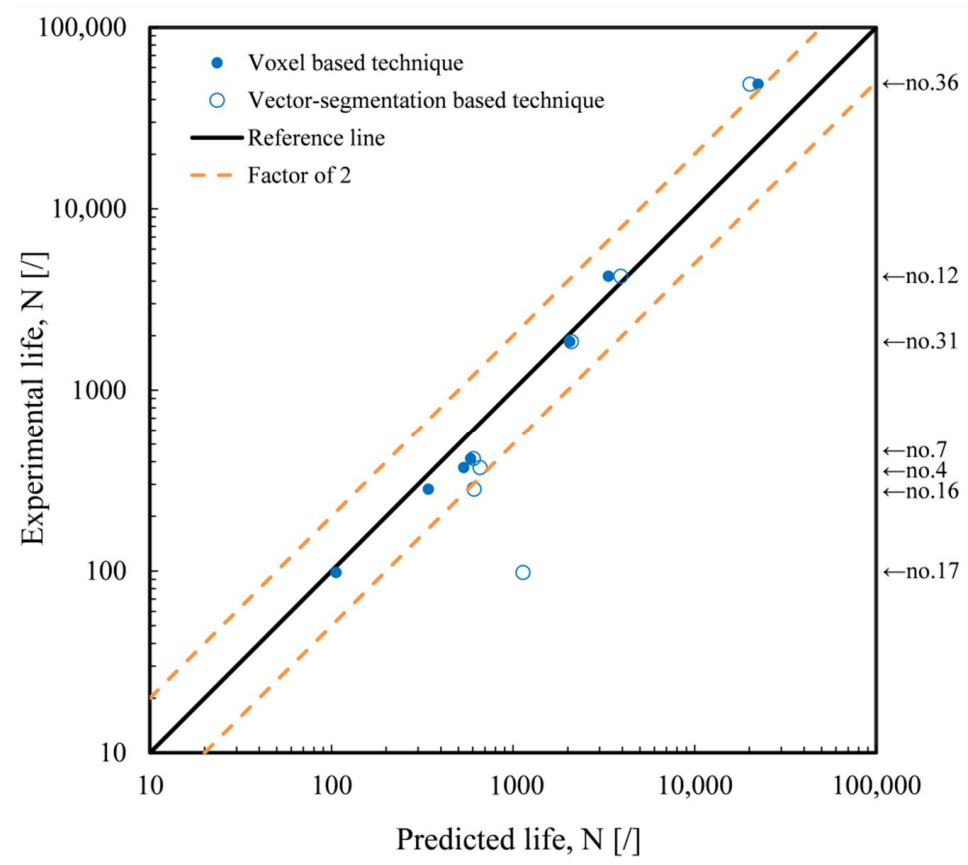

Figure 11. Comparison of experimentally determined and numerically predicted fatigue lives for porous specimens. 
The geometrical characteristics, which follow from the pressure die-casting process and were described in Section 2, can now be linked to the results of the numerical analyses for both pore-characterisation techniques. A comparison of local geometric peculiarities of the specimens and the predicted fatigue lives is given in Table 6. In this context, Figure 4, which shows critical failure sections, is very helpful for identification of the true reasons for the accelerated fatigue-crack propagation. It can be concluded from the summarised results in Table 6 and Section 2 that the most damaging pores are the ones that emerge as a consequence of the shrinkage porosity. They have the highest notch effect and are the most difficult for geometric characterisation, regardless of the applied technique. For such geometric inhomogeneities the voxel technique has a little advantage, because it can better follow the rippled pore boundaries. However, to properly account for these geometric effects also the Coffin-Manson (C-M) curve for the homogeneous base material should be estimated as well as possible. Namely, if its scatter is significant, the predicted fatigue life does not correspond well to the experimentally determined durability in the cases where the fatigue failure is governed by a combination of different influential factors, e.g., see Specimen no. 36.

Table 6. Qualitative analysis for different techniques of pore characterisation.

\begin{tabular}{|c|c|c|}
\hline Spec. no. & Voxel Based Technique & Vector-Segmentation Based Technique \\
\hline 12 & $\begin{array}{l}\text { Homogeneous pore distribution and absence of disc-like } \\
\text { pores is favourable for estimating the ellipsoids with } \\
\text { this technique. }\end{array}$ & $\begin{array}{l}\text { Presence of dominant pores with regular geometry is } \\
\text { favourable for this technique. }\end{array}$ \\
\hline 31 & $\begin{array}{l}\text { Smaller shrinkage-based pores and bigger gas-based } \\
\text { pores have disc-like shape. The bigger dominant pores } \\
\text { are in good agreement with the modelled ellipsoids. } \\
\text { Consequently, the predicted fatigue life agrees well with } \\
\text { the experimentally determined result. }\end{array}$ & $\begin{array}{c}\text { There are no intersections for the bigger dominant pores. } \\
\text { Since the bigger oval pores have regular shape they are } \\
\text { well modelled with this technique and the predicted } \\
\text { fatigue life agrees well with the experimentally } \\
\text { determined result. }\end{array}$ \\
\hline 36 & $\begin{array}{l}\text { Small volumetric pores are present and the specimen } \\
\text { has the smallest porosity level } p \text {. Pores are well } \\
\text { characterised by the voxel technique, but the fatigue life } \\
\text { is poorly predicted, because the loading level in the less } \\
\text { steep part of the C-M curve. }\end{array}$ & $\begin{array}{l}\text { A conclusion is similar as for the voxel technique; the } \\
\text { geometric characterisation of porosity was simple also } \\
\text { with the vector-segmentation technique. }\end{array}$ \\
\hline 17 & $\begin{array}{l}\text { The porosity level } p \text { is small, pores are isolated, have } \\
\text { irregular shapes, and are very thin. Voxel technique for } \\
\text { porosity characterisation is advantageous in this case. }\end{array}$ & $\begin{array}{l}\text { Thin and rippled pores are difficult to characterise with } \\
\text { the vector-segmentation technique. The notch effect is } \\
\text { underestimated, because the bigger and more regular } \\
\text { ellipsoid is fitted to a cluster of smaller irregular pores. }\end{array}$ \\
\hline 16 & $\begin{array}{l}\text { For the highest porosity level } p \text { the geometric pore } \\
\text { characterisation was difficult. The voxel technique is } \\
\text { well suited for the separation of the intersected pores, } \\
\text { but the pore volumes are poorly identified. }\end{array}$ & $\begin{array}{l}\text { The biggest problem of the vector- segmentation } \\
\text { technique in this case was the separation of the } \\
\text { intersected pores. The pore intersections were } \\
\text { significant in this case, because of the pore sizes. }\end{array}$ \\
\hline 4 & $\begin{array}{l}\text { Since there is only one big dominant pore in this case the } \\
\text { geometric characterisation of porosity was easy and the } \\
\text { predicted fatigue life agrees well with the } \\
\text { experimentally determined result. }\end{array}$ & $\begin{array}{l}\text { Big volumetric pores are well characterised with this } \\
\text { technique. Smaller deviations occur only for the } \\
\text { orientation vectors of the dominant pore. }\end{array}$ \\
\hline 7 & $\begin{array}{l}\text { A centred cluster of mid-size pores is present in this } \\
\text { sample. In general the pore geometry was reasonably } \\
\text { well modelled in this case with some smaller deviations } \\
\text { at the sharp pore boundaries. }\end{array}$ & $\begin{array}{c}\text { Since some pores intersect they are not so well modelled } \\
\text { with the vector-segmentation technique, which is the } \\
\text { main drawback of this method. Consequently, the } \\
\text { predicted fatigue life is worse than for the voxel } \\
\text { technique. }\end{array}$ \\
\hline
\end{tabular}

From the combination of the experimental and numerical results it can be concluded that the most damaging effect is caused by the disc-like pores that result in the most significant notch effects. Significant fatigue damage is also caused by the larger regular spherical pores with an asymmetrical position in the critical cross-section like in Specimen no. 16. In this specimen the pores of relatively regular shape were much larger on one side of the cross-section than on the other side, which adds to the notch effect. It turned out that pores of rather homogeneous sizes and more even distribution in the critical cross-section 
are more favourable from the standpoint of the achieved fatigue life, despite the larger porosity level.

\section{Discussion}

A thorough study of the fatigue durability for the porous structures requires a multidisciplinary approach from the following fields: (i) metallurgy for specimen preparation and porosity classification; (ii) mathematics for an exact description of the geometric inhomogeneities; and (iii) mechanical engineering for performing the fatigue-life experiments and simulations. In our case the geometric inhomogeneities (voids) in the high-pressure die-casted specimens from the AlSi9Cu3 alloy were significantly larger than the other material defects. For this reason, it was presumed that the macro porosity is the primary driver of the fatigue-crack initiation and propagation. Consequently, the method for calculating the fatigue damage considered only the macro-pore defects that can be identified with the $\mu$-CT scanning. Besides that, a threshold limit of $0.01 \mathrm{~mm}$ for the largest ellipsoid axis was considered when reproducing the identified pores in the 3D model. If the largest ellipsoid axis was smaller than the threshold, the ellipsoid was not included into the 3D model. The applied threshold value was determined as a trade-off between the accuracy of the geometric modelling and the processing time for the numerical simulations on the basis of the preliminary sensitivity analysis, in which different threshold criteria were studied. If the threshold is too large, some influential pores can be lost. On the other hand, if the threshold is too small, the number of finite elements and nodes in the FE model becomes inflated beyond a reasonable limit, which significantly increases the processing time without a significant influence on the final results.

The main focus of this research was to establish the context between the quality of the geometric pore parameterisation and the accuracy of the fatigue-life prediction. In our previous research [21] it turned out that significant differences between the predicted and experimentally determined fatigue lives occurred for some specimens (e.g., Specimen no. 36). That is why it was decided to use another technique for the geometric parameterisation of the porosity. From the result of this study, it seems that the poor fatigue-life prediction for Specimen no. 36 is not caused by the inaccuracy of the pore characterisation. It is more likely that the poor prediction is a consequence of the fact that the strain amplitude for this specimen was the smallest and was already in the high-cycle fatigue domain, as explained before.

A major characteristic of the brittle materials, which holds also for the AlSi9Cu3 alloy, is that the crack growth is very rapid after the crack initiation. This means that the number of load cycles for crack initiation $N_{i}$ is similar to the number of load cycles for the fatigue failure $N_{f}$. However, when there is significant porosity, crack propagation should be somehow introduced into the fatigue-prediction models. The usual approach would be to follow the fracture mechanic principles, which need additional material parameters (and experiments) for estimating the sigmoid $\mathrm{d} a / \mathrm{d} N-\Delta K$ curve for the crack growth. On the other hand, in our case the distances between the neighbouring pores were small. When this fact is combined with the brittle material properties, the complete process of the crack initiation and propagation could be modelled using the continuum-damage mechanics principle, which was applied in our research.

The most demanding task in the simulation process is the meshing of the 3D models. Due to the complicated and irregular geometry of the specimens it was only possible with the C3D4 tetrahedron finite elements in Abaqus. The meshing process failed if the other FE types (hex-brick or wedge) were used. The authors of this study are aware of the fact that custom-made commercial meshing software and techniques already exist [39]. However, one of the objectives of the research was to obtain usable numerical results as quickly as possible with a minimum amount of commercially available software involved. Additional software requirements always result in additional costs for their acquisition and/or usage. If the sizes of the FE models are compared (see Table 5) it can be concluded that the vector segmentation technique results in smaller FE models on average, though the difference to 
the voxel technique is not significant. The most demanding inhomogeneities to model are the thin disc-like pores. If it is not possible to model them automatically with the presented algorithm(s) they need to be modelled manually. In this way a dominant, branched, thin disc pore in Specimen no. 17 was modified by hand using the 3D modeller Catia V5.

To summarise our research, it is possible to conclude that there are many causes for fatigue-crack initiation and growth in high-pressure die-casted parts, e.g., micro-cracks, inclusions, impurities, etc. In spite of all this the presented approach makes it possible to predict the fatigue life for high-pressure die-cast structures with significant macro porosity.

\section{Conclusions}

From the experimental observations and numerical simulations, the main outcomes of the presented research can be summarised as follows:

- $\quad$ Direct meshing of the 3D models that are obtained using the $\mu$-CT scanning is impossible, because of complicated and often poorly closed surfaces. Consequently, it was decided to parameterise the porous structure with ellipsoids.

- Two algorithms for the determination of the ellipsoids from the $\mu$-CT scans were compared and assessed. For irregular disc-like pores the voxel technique outperforms the vector-segmentation technique. In contrast, regular spherical pores are better modelled using the vector-segmentation technique.

- The fatigue life was predicted using the Brown-Miller (Morrow) criterion, which is more conservative than the Normal-strain (Morrow) criterion [36]. When evaluating the numerical structure, it is important that the predictions are on the safe side.

- With the application of continuum-damage mechanics it is possible to estimate the crack initiation and growth in the porous structures. In the article this significant upgrade of the fatigue-life prediction method is presented, which introduces finiteelement annihilation on the basis of the fatigue damage.

Author Contributions: Conceptualization, D.T. and J.K.; methodology, D.T., Ž.V. and J.K.; investigation, D.T. and J.K.; data curation, Ž.V., P.M.K. and G.J.; software, D.T., Ž.V., P.M.K. and G.J.; writing-original, D.T.; writing-review \& editing J.K. and D.T. All authors have read and agreed to the published version of the manuscript.

Funding: This research was funded by the Slovenian Research Agency (ARRS), grant research programmes P2-0182 (R\&D evaluations-Razvojna vrednotenja) and P1-0292 (Topology, geometry and nonlinear analysis-Topologija, geometrija in nelinearna analiza).

Acknowledgments: The authors would like to thank Tomaz Bester for his technical support in performing the low-cycle fatigue experiments.

Conflicts of Interest: The authors declare no conflict of interest. The funders had no role in the design of the study; in the collection, analyses, or interpretation of data; in the writing of the manuscript, or in the decision to publish the results.

\section{References}

1. Wenlong, S.; Xiaokai, C.; Lu, W. Analysis of Energy Saving and Emission Reduction of Vehicles Using Light Weight Materials. Energy Procedia 2016, 88, 889-893. [CrossRef]

2. Linder, J.; Arvidsson, A.; Kron, J. The influence of porosity on the fatigue strength of high-pressure die cast aluminium. Fatigue Fract. Eng. Mater. Struct. 2006, 29, 357-363. [CrossRef]

3. Vicario, I.; Crespo, I.; Plaza, L.M.; Caballero, P.; Idoiaga, I.K. Aluminium Foam and Magnesium Compound Casting Produced by High-Pressure Die Casting. Metals 2016, 6, 24. [CrossRef]

4. Krstulović-Opara, L.; Vesenjak, M.; Duarte, I.; Ren, Z.; Domazet, Ž. Infrared Thermography as a Method for Energy Absorption Evaluation of Metal Foams. Mater. Today Proc. 2016, 3, 1025-1030. [CrossRef]

5. Szalva, P.; Orbulov, I.N. Fatigue testing and non-destructive characterization of AlSi9Cu3(Fe) die cast specimens by computer tomography. Fatigue Fract. Eng. Mater. Struct. 2020, 43, 1949-1958. [CrossRef]

6. Taheri, F.; Lu, Y.; Mehrzadi, M. Microstructure and Fatigue Characteristic of AM60B Magnesium Alloy. Metals 2012, 2, 411-440. [CrossRef]

7. Gagg, C. Forensic Engineering: The Art and Craft of a Failure Detective; CRC Press, Taylor \& Francis Group, LLC: Boca Raton, FL, USA, 2020; p. 420. 
8. Withey, P.A. Fatigue failure of the de Havilland comet I. Eng. Fail. Anal. 1997, 4, 147-154. [CrossRef]

9. Bižal, A.; Klemenc, J.; Fajdiga, M. Modelling the fatigue life reduction of an AlSi9Cu3 alloy caused by macro-porosity. Eng. Comput. 2015, 31, 259-269. [CrossRef]

10. Boyer, H.E. Atlas of Fatigue Curves: Senior Technical Editor American Society for Metals; ASM lnternational: Materials Park, OH, USA, 1986; ISBN 978-0-87170-214-2.

11. McEvily, A.J. Atlas of Stress-Corrosion and Corrosion Fatigue Curves; ASM International: Materials Park, OH, USA, 1990; ISBN 978-0-87170-374-3.

12. Manson, S.S.; Halford, G.R. Fatigue and Durability of Structural Materials; ASM International: Materials Park, OH, USA, 2006; p. 456.

13. Liu, A.F. Mechanics and Mechanisms of Fracture: An Introduction; ASM International: Materials Park, OH, USA, 2005 ; p. 500.

14. Miner, M.A. Cumulative damage in fatigue. J. Appl. Mech. 1945, 12, A159-A164.

15. Palmgren, A. Die lebensdauer von kugellagern. Z. VDI. 1924, 68, 339-341.

16. Ciavarella, M.; D'antuono, P.; Papangelo, A. On the connection between Palmgren-Miner rule and crack propagation laws. Fatigue Fract. Eng. Mater. Struct. 2018, 41, 1469-1475. [CrossRef]

17. Le, V.-D.; Saintier, N.; Morel, F.; Bellett, D.; Osmond, P. Investigation of the effect of porosity on the high cycle fatigue behaviour of cast Al-Si alloy by X-ray micro-tomography. Int. J. Fatigue 2018, 106, 24-37. [CrossRef]

18. Jiang, S.; He, M.; Li, X.; Tang, C.; Liu, J.; Liu, S. Modeling and estimation of hole-type flaws on cracking mechanism of SiC ceramics under uniaxial compression: A 2D DEM simulation. Theor. Appl. Fract. Mech. 2020, 105, 102398. [CrossRef]

19. Wang, X.; Zhang, M.; Jivkov, A.P. Computational technology for analysis of 3D meso-structure effects on damage and failure of concrete. Int. J. Solids Struct. 2016, 80, 310-333. [CrossRef]

20. Borovinšek, M.; Vesenjak, M.; Jože, M.; Ren, Z. Computational Reconstruction of Scanned Aluminum Foams for Virtual Testing. J. Serb. Soc. Comput. Mech. 2008, 2, 16-28.

21. Tomažinčič, D.; Borovinšek, M.; Ren, Z.; Klemenc, J. Improved prediction of low-cycle fatigue life for high-pressure die-cast aluminium alloy AlSi9Cu3 with significant porosity. Int. J. Fatigue 2021, 144, 106061. [CrossRef]

22. Di Giovanni, M.T.; de Menezes, J.T.O.; Cerri, E.; Castrodeza, E.M. Influence of microstructure and porosity on the fracture toughness of Al-Si-Mg alloy. J. Mater. Res. Technol. 2020, 9, 1286-1295. [CrossRef]

23. Hou, Z.; Chen, S.; Sun, Q.; Wei, X.; Lv, W. Experimental research on fatigue characteristics of X12Cr13 stainless steel. J. Mater. Res. Technol. 2020, 9, 3230-3240. [CrossRef]

24. Murakami, Y.; Endo, M. Effects of defects, inclusions and inhomogeneities on fatigue strength. Int. J. Fatigue 1994, 16, 163-182. [CrossRef]

25. Freitas, P.; Laugesen, R.S.; Liddell, G.F. On convex surfaces with minimal moment of inertia. J. Math. Phys. 2007, 48, 122902. [CrossRef]

26. Papastavridis, J.G. Analytical Mechanics: A Comprehensive Treatise on the Dynamics of Constrained Systems; World Scientific Publishing Company: Singapore, 2014; p. 1392.

27. Hatcher, A. Algebraic Topology, 1st ed.; Cambridge University Press: Cambridge, UK, 2001; p. 551.

28. Beer, F.; Johnston, E.; Mazurek, D.; Cornwell, P.; Self, B.; Sanghi, S. Vector Mechanics for Engineers Statics and Dynamics, 12th ed.; McGraw-Hill Education: New York, NY, USA, 2019; p. 1472.

29. Gallier, J.; Xu, D. A Guide to the Classification Theorem for Compact Surfaces (Geometry and Computing 9); Springer: Berlin, Germany, 2013; p. 183.

30. Tomažinčič, D.; Nečemer, B.; Vesenjak, M.; Klemenc, J. Low-cycle fatigue life of thin-plate auxetic cellular structures made from aluminium alloy 7075-T651. Fatigue Fract. Eng. Mater. Struct. 2019, 42, 1022-1036. [CrossRef]

31. Kramberger, J.; Nečemer, B.; Glodež, S. Assessing the cracking behavior of auxetic cellular structures by using both a numerical and an experimental approach. Theor. Appl. Fract. Mech. 2019, 101, 17-24. [CrossRef]

32. Tomažinčič, D.; Vesenjak, M.; Klemenc, J. Prediction of static and low-cycle durability of porous cellular structures with positive and negative Poisson's ratios. Theor. Appl. Fract. Mech. 2020, 106, 102479. [CrossRef]

33. Tomazincic, D.; Sedlacek, M.; Podgornik, B.; Klemenc, J. Influence of different micro-imprints to fatigue life of components. Mater. Perform. Charact. 2017, 6, 79-95. [CrossRef]

34. Manson, S.S. Fatigue: A complex subject-Some simple approximations. Exp. Mech. 1965, 5, 193-226. [CrossRef]

35. Dowling, N.E. Mechanical Behaviour of Materials, 4th ed.; Pearson Education Limited: London, UK, $2012 ;$ p. 960.

36. Corp, D.S.S. SIMULIA Fe-Safe User Guide, 1st ed.; Dassault Systemes: Vélizy-Villacoublay Cedex, France, 2019 ; p. 445.

37. Brown, M.W.; Miller, K.J. A theory for fatigue failure under multiaxial stress-strain conditions. Proc. Inst. Mech. Eng. 1973, 187, 745-755. [CrossRef]

38. Sunder, R. A unified model of fatigue kinetics based on crack driving force and material resistance. Int. J. Fatigue 2007, 29, 1681-1696. [CrossRef]

39. Sohn, D.; Cho, Y.-S.; Im, S. A novel scheme to generate meshes with hexahedral elements and poly-pyramid elements: The carving technique. Comput. Methods Appl. Mech. Eng. 2012, 201-204, 208-227. [CrossRef] 